\title{
Overexpression and lack of copy number variation in the BMI-1 gene in human glioma
}

\author{
SIBIN MADATHAN KANDY ${ }^{1}$, DHANANJAYA ISHWARA BHAT ${ }^{2}$, LAVANYA CHOPPAVARAPU ${ }^{1}$, \\ ARATI SUVATHA $^{1}$ and CHETAN GHATI KASTURIRANGAN ${ }^{1}$ \\ Departments of ${ }^{1}$ Human Genetics and ${ }^{2}$ Neurosurgery, National Institute of Mental Health and Neurosciences, \\ Bangalore, Karnataka 560029, India
}

Received October 30, 2014; Accepted August 20, 2015

DOI: $10.3892 / \mathrm{ol} .2015 .3686$

\begin{abstract}
Malignant gliomas are neoplasms of the brain that are associated with a poor prognosis. The B-cell-specific Moloney murine leukemia virus integration site 1 (BMI-1) gene is one of the major cancer stem cell factors responsible for treatment failure in glioma. In the present study, the DNA-RNA-protein alterations in the BMI-1 gene were assessed in 50 glioma samples. Copy number variations in the BMI-1 gene were analyzed using $\mathrm{SYBR}^{\circledR}$ Green quantitative polymerase chain reaction. Gene expression analysis was performed using a Taqman assay and protein quantitation was performed using western blotting. A comparative $\mathrm{Ct}$ analysis showed the absence of copy number variations in all glioma samples. BMI-1 mRNA expression was found to be overexpressed in 36 out of 50 samples $(72.0 \%)$, and 37 out of 50 samples showed overexpression $(74.0 \%)$ of BMI-1 protein; this was statistically significant when compared with non-glioma tissues. It was observed that the protein and RNA expression in glioma were concordant. In this study on the BMI-1 gene, transcription and translation in glioma were observed and BMI-1 overexpression was found to be a common phenomenon.
\end{abstract}

\section{Introduction}

Gliomas are tumors that arise from glial cells, and malignant gliomas are the most common primary intrinsic brain tumors of adulthood. Glioblastomas account for $15.6 \%$ of all primary brain tumors and $45.2 \%$ of primary malignant brain tumors. The estimated relative survival rates for glioblastoma are fairly low, with $<5 \%$ of patients predicted to survive for five years post-diagnosis (1).

B-cell-specific Moloney murine leukemia virus integration site 1 (BMI-1) protein is a member of the polycomb

Correspondence to: Dr Chetan Ghati Kasturirangan, Department of Human Genetics, National Institute of Mental Health and Neurosciences, Hosur Road, Bangalore, Karnataka 560029, India E-mail: drchetangk@gmail.com

Key words: glioma, BMI-1, copy number, overexpression group of proteins, initially isolated as an oncogene involved in leukemia (2). The gene is located on chromosome 10p12.22 and has 10 exons. BMI-1 has been demonstrated to be a key regulatory factor for the determination of a cellular phenotype in a variety of therapy-resistant cancers, including glioma (3-9). A previous study showed that BMI-1 levels increased in $79 \%$ of head and neck carcinoma patients, and a positive correlation was found between these BMI-1 levels and a lack of response to radiotherapy or chemotherapy (10). Abdouh et al (2009) reported that BMI-1 is expressed in glioblastoma tumors, is highly enriched in cluster of differentiation (CD) $133^{+}$tumor-initiating cells and is necessary for tumor cell growth (11).

There are only a few studies that have analyzed the role of BMI-1 gene alterations in glioma in clinical samples $(12,13)$. A DNA-RNA-protein analysis on the same sample could provide a complete picture in order to establish the mechanism of BMI-1 regulation. The present study analyzed the copy number variations and expression of BMI-1 at the RNA and protein levels, and its correlation with clinical characteristics.

\section{Materials and methods}

Sample. Glioma samples were collected from the 50 patients, enrolled between September 2011 and September 2012, who underwent surgery in the Department of Neurosurgery at the National Institute of Mental Health and Neurosciences (NIMHANS; Bangalore, India). Informed consent was obtained from all patients included in the study. Tissues were bisected and one half was placed in RNAlater (Sigma-Aldrich, St. Louis, Missouri, USA) and snap frozen in liquid nitrogen, then kept at $-80^{\circ}$ until the isolation of the DNA. The other half was sent for histopathological analysis. Histopathological diagnosis was made using the World Health Organization (2007) grading system (14) in the Department of Neuropathology. Control brain tissues were collected from 5 patients undergoing anterior temporal lobectomy for mesial temporal sclerosis. The study was approved by the NIMHANS Human Ethics Committee.

DNA and RNA isolation and quantification. Tissues were analyzed histologically and those containing $>95 \%$ tumor cells were used for further analysis. DNA and RNA isolation 
was performed using an All Prep DNA/RNA Mini isolation kit (Qiagen GmbH, Hilden, Germany) and quantified by Nanodrop ND 2000c (Thermo Fisher Scientific, Waltham, MA, USA). DNA Samples with a purity of 1.75-1.85 and RNA samples with a purity of $1.95-2.05\left(\mathrm{~A}_{260 / 280}\right)$ were used in this study. RNA stability was checked by formaldehyde agarose gel electrophoresis.

Copy number variation of BMI-1 using quantitative polymerase chain reaction. Quantitative PCR amplification was performed on the Applied Biosystems 7500 (Applied Biosystems, Foster City, CA, USA), using SYBR ${ }^{\circledR}$ Select master mix (Invitrogen, Life Technologies, Carlsbad, CA, USA) with a total reaction volume of $20 \mu \mathrm{l}$. The PCR mixtures were then subjected to $50^{\circ} \mathrm{C}$ for UDG activation for $2 \mathrm{~min}$ and activation at $95^{\circ} \mathrm{C}$ for 2 min, followed by 40 cycles of denaturation at $95^{\circ} \mathrm{C}$ for $15 \mathrm{sec}$, annealing at $53^{\circ} \mathrm{C}$ for $15 \mathrm{sec}$ and extension at $72^{\circ} \mathrm{C}$ for $60 \mathrm{sec}$. Each template-primer pair was tested in three replicates to estimate the mean $\mathrm{Ct}$. The comparative $\mathrm{Ct}$ method was used to check the copy number variation in the BMI-1 gene. The primer sequence was as follows: $\beta$-actin forward, 5'-GCATTTAGG TAAGGGGTGGA-3' and reverse, 5'-GGGTACACAGACGAA GCAGA-3'; and BMI-1 forward, 5'-TGTGTGCTTTGTGGA GGGTA-3' and reverse, 5'-CATTTCCACAGATTGCAGGA-3'.

RNA extraction and reverse transcription-quantitative PCR. Total RNA $(1 \mu \mathrm{g})$ was reverse transcribed into cDNA using MMLV-reverse transcriptase, oligo-dT, dNTPs and buffer following the manufacturer's instructions (Life Technologies). The sequences of the BMI-1 and GAPDH detection probes and primers were as follows: BMI-1 sense, 5'-CTGGTTGCCCAT TGACAGC-3'; BMI-1 antisense, 5'-CAGAAAATGAATGCG AGCCA-3'; probe for BMI-1, 5'-CAGCTCGCTTCAAGATGG CCGC-3', labeled with FAM and TAMRA as the reporter dye; GAPDH sense, 5'-GAAGGTGAAGGTCGGAGTCAAC-3'; GAPDH antisense, 5'-CAGAGTTAAAAGCAGCCCTGG T-3'; GAPDH probe, 5'-TTTGGTCGTATTGGGCGCCT-3', labeled with VIC dye. The quantitative assay amplified $1 \mu 1$ of cDNA in three replicates using the aforementioned primers and probes, and the Taqman Universal master mix (Applied Biosystems). Comparative analysis by the $2^{-\Delta \Delta \mathrm{Ct}}$ method was used to compare the expression in each gene.

Western blotting. Whole-cell protein extracts were obtained from all 50 tissues. Cell lysates were prepared in cold lysis buffer [50 mM Tris, $150 \mathrm{mM} \mathrm{NaCl}, 1 \mathrm{~mol} / 1$ EDTA, $0.1 \%$ sodium dodecyl sulfate, $1 \%$ Triton X-100, $1 \mathrm{~mol} / 1$ phenylmethylsulfonyl fluoride (pH 8.0); SRL Ltd., Bangalore, India]. The lysate was collected and stored at $-80^{\circ} \mathrm{C}$. The protein content in the lysates was measured by Bradford assay. For western blot analysis, $50 \mu \mathrm{g}$ protein was resolved on $12 \%$ SDS-PAGE gels, transferred onto polyvinyldifluoride membranes (Bio-Rad Laboratories Inc., Hercules, CA, USA) and subsequently incubated in blocking buffer (5\% bovine serum albumin, 1\% Tween 20 in $20 \mathrm{mmol} / 1$ Tris-buffered saline (pH 7.6); SRL Ltd.] for $1 \mathrm{~h}$. The blots were incubated with mouse anti-human monoclonal $\mathrm{IgG}_{1}$ antibody against BMI-1 (\#sc-390443; 1:1,000 dilution), followed by rabbit anti-mouse IgG horseradish peroxidase-conjugated antibody (\#sc-358914; 1:5,000 dilution) (both Santa Cruz Biotechnology Inc., Dallas, TX, USA), and detected by enhanced chemiluminescence kit (Bio-Rad Laboratories Inc.) according to the manufacturer's instructions. Equal loading of protein was confirmed by stripping the blots and re-probing with monoclonal mouse anti-human $\beta$-tubulin antibody (\#sc-58882; 1:2,000 dilution; Santa Cruz Biotechnology Inc.). Bands were detected by chemiluminescence and analyzed using ImageJ software (National Institutes of Health, Bethesda, MD, USA).

Statistical analysis. R-2.3.1 (R Foundation for Statistical Computing, Vienna, Austria) was used for the statistical analysis. Due to the non-normal distribution of the samples, the statistical evaluation was performed using non-parametric tests. Comparison between mRNA and protein expression levels in the different grades of glioma was performed using the Kruskal-Wallis test. Correlation between mRNA and protein was analyzed using Spearman's correlation test. $\mathrm{P}<0.05$ was used to indicate a statistically significant difference.

\section{Results}

Patient details. A total of 50 patients with varying grades of glioma, enrolled between 2011 and 2012, were included in this study. All tumors were pathologically confirmed as glioma, and the patients underwent radiological and histopathological examinations to establish the clinical profile. The age of the patients ranged from 8-60 years (mean, 35.6 14.86 ).

BMI-1 gene copy number variation in glioma. BMI-1 gene amplification analysis was performed using SYBR Green quantitative PCR in all tumor samples and non-glioma brain tissues. The copy number variation was analyzed in comparison with the $\beta$-actin gene. The comparative $\mathrm{Ct}$ value analysis did not show any difference between the BMI- 1 and $\beta$-actin genes in the glioma samples or the non-glioma brain tissues.

BMI-1 mRNA expression and correlation of clinical data. The BMI-1 mRNA levels were analyzed in all the glioma samples. BMI-1 mRNA expression was found to be overexpressed in the glioma tissues compared with the non-glioma samples. In total, 36 out of 50 samples demonstrated overexpression (72\%.0), which was statistically significant when compared with the non-glioma control tissues $(\mathrm{P}=0.01)$. The median fold-change of expression was 2.055. The mRNA expression ranged from 1.41-fold to 60.97-fold. Grade-wise gene expression analysis was performed and BMI-1 was found to be expressed more in high-grade glioma than in low-grade glioma (Kruskal-Wallis rank sum test; $\mathrm{P}=0.025$ ), as shown in Fig. 1 . The clinical details are provided in Table I.

BMI-1 protein expression in glioma and correlation of clinical data. BMI-1 protein levels were analyzed in all glioma tissue samples. BMI-1 protein expression was found to be overexpressed in the glioma tissues compared with the non-glioma samples upon western blot analysis (Fig. 2). In total, 37 out of 50 samples demonstrated overexpression (74.0\%), which was statistically significant compared with the non-glioma control tissues $(\mathrm{P}=0.037)$. The median fold-change of expression was 2.0408. The protein expression ranged from 1.47-fold to 16.36-fold. Grade-wise gene expression analysis was performed and BMI-1 was found to be expressed more in 
Table I. BMI-1 mRNA and protein expression data with clinical characteristics.

\begin{tabular}{|c|c|c|c|c|c|}
\hline Characteristics & No. of patients & $\begin{array}{l}\text { BMI-1 mRNA expression } \\
\text { (mean fold-change) }\end{array}$ & P-value & $\begin{array}{l}\text { BMI-1 protein expression } \\
\text { (mean fold-change) }\end{array}$ & P-value \\
\hline Age, years & & & 0.467 & & 0.907 \\
\hline$\leq 35$ & 24 & 7.10 & & 1.97 & \\
\hline$>35$ & 26 & 7.89 & & 2.77 & \\
\hline Gender & & & 0.066 & & 0.276 \\
\hline Male & 31 & 9.56 & & 1.95 & \\
\hline Female & 19 & 4.17 & & 2.54 & \\
\hline Grade & & & 0.025 & & 0.024 \\
\hline Low & 8 & 1.79 & & 1.43 & \\
\hline High & 42 & 8.60 & & 2.67 & \\
\hline Tumor type & & & 0.448 & & 0.8253 \\
\hline Astrocytoma & 12 & 4.21 & & 1.76 & \\
\hline Oligodendroglioma & 22 & 8.96 & & 2.49 & \\
\hline Glioblastoma multiforme & 16 & 7.99 & & 2.35 & \\
\hline
\end{tabular}
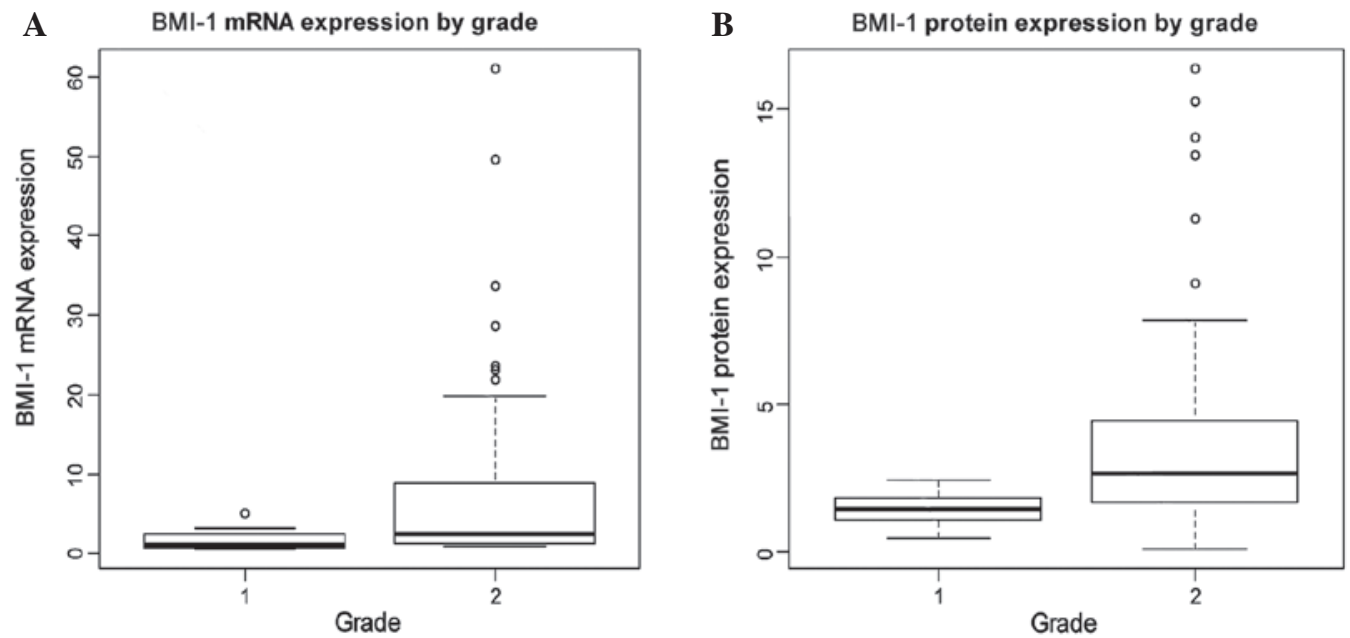

Figure 1. Box plot showing (A) BMI-1 mRNA and (B) protein expression by grade. 1, low grade; 2, high grade. Individual circles represent sample values outside of standard deviation.

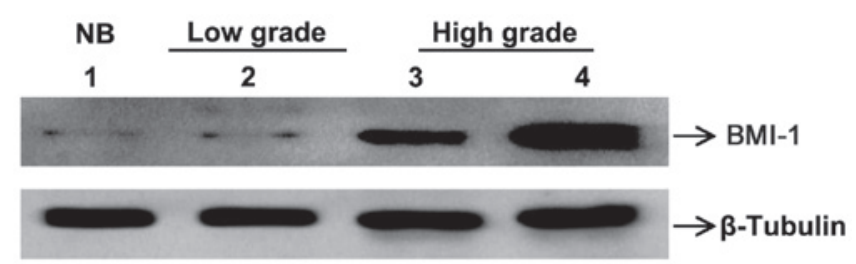

Figure 2. Western blotting showing BMI-1 protein overexpression in glioma. NB, non-glioma brain tissue.

high-grade glioma than in low-grade glioma (Kruskal-Wallis rank sum test; $\mathrm{P}=0.024$ ), as shown in Fig. 1. There were no other clinical correlations with protein expression (Table I).

Correlation of BMI-1 mRNA and protein expression. The correlation between BMI-1 mRNA and protein levels was assessed by Spearman's correlation test. A positive correlation was found with a coefficient $\mathrm{Q}$-value of 0.474 (Fig. 3); this was statistically significant $(\mathrm{P}=0.0005)$. This indicates that the protein expression was concordant with the mRNA expression, and suggests that there may not be much post-translational regulation in this protein in glioma.

\section{Discussion}

Our understanding of the pathophysiology of glioma has progressed in recent years. New studies are focused on targeting the cancer stem cells that are responsible for treatment resistance. A few cancer stem cell factors, such as CD133, Nestin and CD44, are being considered as potent biomarkers for therapeutic targeting. The BMI-1 gene is one of the stem cell factors that has a promising role. BMI-1 has been found to be overexpressed in gliomas and to interact with other oncogenes to make them resistant to anticancer drugs (15-19). 

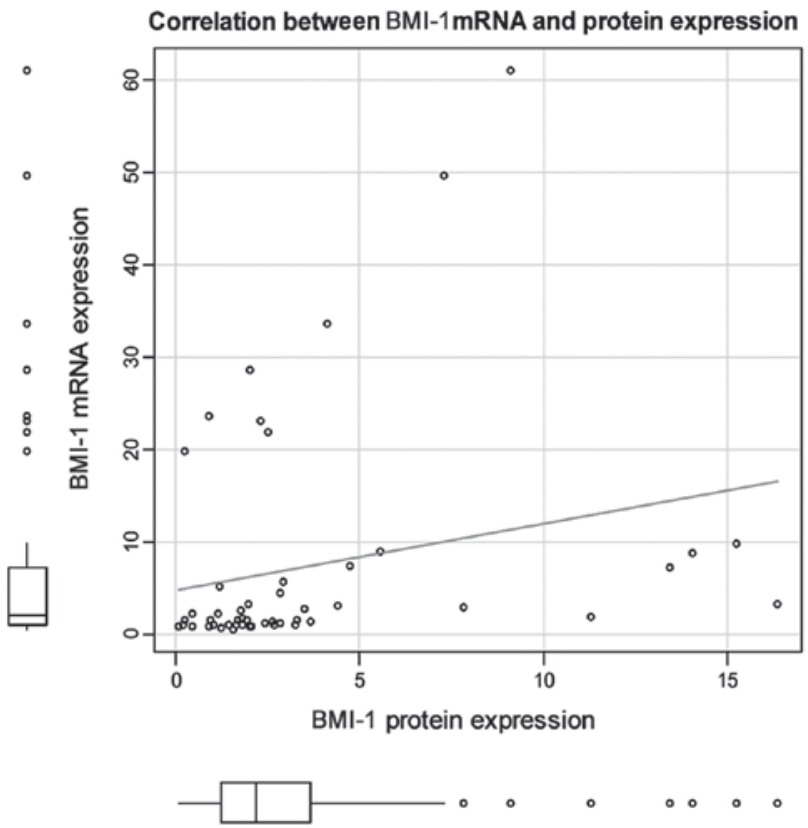

Figure 3. Graph showing correlation between BMI-1 mRNA and protein expression.

BMI-1 is a component of polycomb repressive complex 1 (PRC1) involved in epigenetic regulation of gene activity (20). Gli1 protein can directly bind to the promoter region of BMI-1 and regulate its expression, and this has been found to be the major external stimuli of BMI-1 (21). BMI-1 is an upstream regulator of the CDKN2A pathway, ultimately downregulating TP53 and RB1 genes, which are involved in cell cycle processes (22). Other downstream pathways include the DNA damage response pathway (23), the phosphatase and tensin homolog-Akt pathway (24), the nuclear factor $\kappa \mathrm{B}$ pathway (25) and the glutathione-reactive oxygen species pathway (22). BMI-1 has been found to be overexpressed in various human cancers, including mammary epithelial cancer, prostate cancer, medulloblastoma, melanoma, neuroblastoma, endometrial carcinoma and non-small cell lung cancer (3-9).

It is important to identify the pattern of expression of BMI-1 and to identify therapeutic targets that will downregulate its expression and reduce the aggressiveness of the tumor. In order to understand the BMI-1 gene alterations and expression, the present study analyzed 50 glioma samples and 5 non-glioma samples, and correlated the results with clinical status. Each sample was analyzed for alterations of BMI-1 expression at all levels (DNA-RNA-protein).

BMI-1 gene alterations are uncommon in human neoplasms and are reported only in Mantle cell lymphomas (MCL) and gliomas. High-level DNA amplification of the 10p23 region, where BMI-1 is located, has been observed in head and neck carcinoma and other solid tumors (26). Beà et al (2001) could not find any gene amplification in the BMI-1 gene in any hematological malignancies except for MCL. The study observed tumors expressing high levels of mRNA and protein without any gene amplification, and concluded that this may be due to unknown mechanisms (26).

Previous studies showed BMI-1 gene alterations such as copy number variations (amplifications and deletions), and overexpression of mRNA and protein in different grades of gliomas (12,13,27-29). Häyry et al (2008) showed that BMI-1 protein was overexpressed in the majority of grade 2-4 gliomas (12). In another study, roughly two-thirds of the total tumors exhibited copy number alterations of BMI-1. It was also shown that there was no correlation between BMI-1 copy number variation and protein expression in glioma (13). Abdouh et al (2009) performed quantitative PCR for the gene amplification analysis and they found that there was no gene amplification, but that there was overexpression of BMI-1 in the glioblastoma samples (11). All the glioma samples in the present study failed to show any copy number variations using the quantitative PCR technique. There is a constant debate over the amplification or deletion status in BMI-1 gene in gliomas and other cancers.

Cenci et al (2012) studied high-grade gliomas and revealed the overexpression of BMI-1 protein in $72.9 \%$ of samples (27). Farivar et al (2013) showed BMI-1 gene expression in various types of pediatric brain tumors and found that gliomas exhibited 5.54-fold more BMI-1 expression when compared with normal brain tissues. The BMI-1 expression and other patho-clinical parameters were also found to be significantly correlated in the study (28). Wu et al observed that the BMI-1 protein expression level in glioma was significantly higher than that in corresponding non-neoplastic brain tissue (29).

The present study showed that BMI-1 mRNA was overexpressed in $72 \%$ of the samples. Low-grade glioma exhibited comparatively less expression. There was no statistical correlation between gender and BMI-1 mRNA expression. BMI-1 protein expression (quantitative) was analyzed by western blotting and BMI-1 protein was found to be overexpressed in $74 \%$ of glioma samples, similar to the previously reported range of $67-99 \%(12,27,29)$. In the present study, it was observed that high-grade gliomas exhibited higher levels of protein expression compared with low-grade gliomas. No difference was found between BMI-1 mRNA and protein expression in the glioma subtypes. High transcriptional activity may be the one true reason for the overexpression of BMI-1 at the RNA and protein levels without copy number variation at the gene level.

BMI-1-knockdown has effectively suppressed cancer cell proliferation in several cancer types $(22,30,31)$. Studies have reported that the blocking of BMI-1 inhibits the proliferation and accelerates the apoptosis of colorectal cancer cells (30), breast cancer cells (31) and ovarian carcinoma (22). The silencing of BMI-1 expression can be a potential therapeutic strategy to eliminate these cancer stem cells from the brain.

In conclusion, the BMI-1 gene plays a major role in glioma pathogenesis. The present study showed that BMI-1 mRNA and protein levels are concordantly high in glioma. A post-transcriptional regulation study is required in order to detect the discrepancy of correlation between DNA alteration and RNA/protein expression.

\section{Acknowledgements}

The authors would like to kindly acknowledge the financial support provided by the Council of Scientific and Industrial Research, New Delhi. This study was also financially supported by Department of Science and Technology-Science and Engineering Research Board, Government of India 
(no. SR/SO/HS-233/2012). The authors would also like to thank the Department of Neuropathology, NIMHANS, for performing the histopathological diagnosis.

\section{References}

1. Ostrom QT, Gittleman H, Farah P, Ondracek A, Chen Y, Wolinsky Y, Stroup NE, Kruchko C and Barnholtz-Sloan JS: CBTRUS statistical report: Primary brain and central nervous system tumors diagnosed in the United States in 2006-2010. Neuro-Oncology 15 (Suppl 2): ii1-ii56, 2013.

2. van Lohuizen M, Verbeek S, Scheljen B, Wientjens E, van der Guidon $\mathrm{H}$ and Berns $\mathrm{A}$ : Identification of cooperating oncogenes in $\mathrm{E}$ mu-myc transgenic mice by provirus tagging. Cell 65 : 737-752, 1991.

3. Datta S, Hoenerhoff MJ, Bommi P, Sainger R, Guo WJ, Dimri M, Band H, Band V, Green JE and Dimri GP: Bmi-1 cooperates with $\mathrm{H}$-Ras to transform human mammary epithelial cells via dysregulation of multiple growth-regulatory pathways. Cancer Res 67: 10286-10295, 2007.

4. Lukacs RU, Memarzadeh S, Wu H and Witte ON: Bmi-1 is a crucial regulator of prostate stem cell self-renewal and malignant transformation. Cell Stem Cell 7: 682-693, 2010

5. Wang X, Venugopal C, Manoranjan B, McFarlane N, O'Farrell E, Nolte S, Gunnarsson T, Hollenberg R, Kwiecien J, Northcott P, et al: Sonic hedgehog regulates Bmil in human medulloblastoma brain tumor-initiating cells. Oncogene 31: 187-199, 2012.

6. Bachmann IM, Puntervoll HE, Otte AP and Akslen LA: Loss of BMI-1 expression is associated with clinical progress of malignant melanoma. Mod Pathol 21: 583-590, 2008.

7. Cui H, Hu B, Li T, Ma J, Alam G, Gunning WT and Ding HF: Bmi-1 is essential for the tumorigenicity of neuroblastoma cells. Am J Pathol 170: 1370-1378, 2007.

8. Engelsen IB, Mannelqvist M, Stefansson IM, Carter SL, Beroukhim R, Øyan AM, Otte AP, Kalland KH, Akslen LA and Salvesen HB: Low BMI-1 expression is associated with an activated BMI-1-driven signature, vascular invasion and hormone receptor loss in endometrial carcinoma. Br J Cancer 98: 1662-1669, 2008.

9. Vonlanthen S, Heighway J, Altermatt HJ, Gugger M, Kappeler A, Borner MM, van Lohuizen M and Betticher DC: The bmi-1 oncoprotein is differentially expressed in non-small cell lung cancer and correlates with INK4A-ARF locus expression. Br J Cancer 84: 1372, 2001.

10. Vormittag L, Thurnher D, Geleff S, Pammer J, Heiduschka G, Brunner M, Grasl MCh and Erovic BM: Co-expression of Bmi-1 and podoplanin predicts overall survival in patients with squamous cell carcinoma of the head and neck treated with radio (chemo) therapy. Int J Radiat Oncol Biol Phys 73: 913-918, 2009.

11. Abdouh M, Facchino S, Chatoo W, Balasingam V, Ferreira J and Bernier G: BMI1 sustains human glioblastoma multiforme stem cell renewal. J Neurosci 29: 8884-8896, 2009.

12. Häyry V, Tynninen O, Haapasalo HK, Wölfer J, Paulus W, Hasselblatt M, Sariola H, Paetau A, Sarna S, Niemelä M, et al: Stem cell protein BMI-1 is an independent marker for poor prognosis in oligodendroglial tumours. Neuropathol Appl Neurobiol 34: 555-563, 2008.

13. Häyry V, Tanner M, Blom T, Tynninen O, Roselli A, Ollikainen M, Sariola H, Wartiovaara K and Nupponen NN Copy number alterations of the polycomb gene BMI1 in gliomas. Acta Neuropathol 116: 97-102, 2008.

14. Louis DN, Ohgaki H, Wiestler OD, Cavenee WK, Burger PC, Jouvet A, Scheithauer BW and Kleihues P: The 2007 WHO classification of tumours of the central nervous system. Acta Neuropathol 114: 97-109, 2007.
15. Hemmati HD, Nakano I, Lazareff JA, Masterman-Smith M, Geschwind DH, Bronner-Fraser M and Kornblum HI: Cancerous stem cells can arise from pediatric brain tumors. Proc Natl Acad Sci USA 100: 15178-15183, 2003

16. Singh SK, Hawkins C, Clarke ID, Squire JA, Bayani J, Hide T, Henkelman RM, Cusimano MD and Dirks PB: Identification of human brain tumour initiating cells. Nature 432: 396-401, 2004.

17. Tso CL, Shintaku P, Chen J, Liu Q, Liu J, Chen Z, Yoshimoto K, Mischel PS, Cloughesy TF, Liau LM and Nelson SF: Primary glioblastomas express mesenchymal stem-like properties. Mol Cancer Res 4: 607-619, 2006.

18. Chen R, Nishimura MC, Bumbaca SM, Kharbanda S, Forrest WF, Kasman IM, Greve JM, Soriano RH, Gilmour LL, Rivers CS, et al: A hierarchy of self-renewing tumor-initiating cell types in glioblastoma. Cancer Cell 17: 362-375, 2010.

19. Huber GF, Albinger-Hegyi A, Soltermann A, Roessle M, Graf N, Haerle SK, Holzmann D, Moch H and Hegyi I: Expression patterns of Bmi-1 and p16 significantly correlate with overall, disease-specific and recurrence-free survival in oropharyngeal squamous cell carcinoma. Cancer 117: 4659-4670, 2011.

20. Vaissière T, Sawan C and Herceg Z: Epigenetic interplay between histone modifications and DNA methylation in gene silencing. Mutat Res 659: 40-48, 2008.

21. Park IK, Morrison SJ and Clarke MF: Bmil, stem cells and senescence regulation. J Clin Invest 113: 175-179, 2004.

22. Wang E, Bhattacharyya S, Szabolcs A, Rodriguez-Aguayo C, Jennings NB, Lopez-Berestein G, Mukherjee P, Sood AK and Bhattacharya R: Enhancing chemotherapy response with Bmi-1 silencing in ovarian cancer. PLoS One 6: e17918, 2011.

23. Liu S, Dontu G, Mantle ID, Patel S, Ahn NS, Jackson KW, Suri $\mathrm{P}$ and Wicha MS: Hedgehog signaling and Bmi-1 regulate self-renewal of normal and malignant human mammary stem cells. Cancer Res 66: 6063-6071, 2006.

24. Song LB, Li J, Liao WT, Feng Y, Yu CP, Hu LJ, Kong QL, $\mathrm{Xu}$ LH, Zhang X, Liu WL, et al: The polycomb group protein Bmi-1 represses the tumor suppressor PTEN and induces epithelial-mesenchymal transition in human nasopharyngeal epithelial cells. J Clin Invest 119: 3626-3636, 2009.

25. Li J, Gong LY, Song LB, Jiang LL, Liu LP, Wu J, Yuan J, Cai JC, He M, Wang L, et al: Oncoprotein Bmi-1 renders apoptotic resistance to glioma cells through activation of the IKK-nuclear factor- $\kappa$ B pathway. Am J Pathol 176: 699-709, 2010.

26. Beà $S$, Tort $F$, Pinyol M, Puig $X$, Hernández L, Hernández $S$, Fernandez PL, van Lohuizen M, Colomer D and Campo E: BMI-1 gene amplification and overexpression in hematological malignancies occur mainly in mantle cell lymphomas. Cancer Res 61: 2409-2412, 2001.

27. Cenci T, Martini M, Montano N, D'Alessandris QG, Falchetti ML, Annibali D, Savino M, Bianchi F, Pierconti F, Nasi S, et al: Prognostic relevance of c-Myc and BMI1 expression in patients with glioblastoma. Am J Clin Pathol 138: 390-396, 2012.

28. Farivar S, Zati Keikha R, Shiari R and Jadali F: Expression of bmi-1 in pediatric brain tumors as a new independent prognostic marker of patient survival. Biomed Res Int 2013: 192548, 2013.

29. Wu Z, Wang Q, Wang L, Li G, Liu H, Fan F, Li Z, Li Y and Tu Y: Combined aberrant expression of Bmil and EZH2 is predictive of poor prognosis in glioma patients. J Neurol Sci 335: 191-196, 2013.

30. Molofsky AV, He S, Bydon M, Morrison SJ and Pardal R: Bmi-1 promotes neural stem cell self-renewal and neural development but not mouse growth and survival by repressing the p16Ink4a and p19Arf senescence pathways. Genes Dev 19: 1432-1437, 2005.

31. Bommi PV, Dimri M, Sahasrabuddhe AA, Khandekar J and Dimri GP: The polycomb group protein BMI1 is a transcriptional target of HDAC inhibitors. Cell Cycle 9: 2663-2673, 2010. 